\title{
Pola Weiss, registrando cuerpos, movimientos y desbordes*
}

POLA WEISS, REGISTERING BODIES, MOVEMENTS AND OVERFLOWS

POLA WEISS, REGISTAR CORPOS, MOVIMENTOS E DERRAPAGENS

\section{María Elena Lucero**}

Cuadernos de Música, Artes Visuales y Artes Escénicas

/ Volumen 13 - Número 1 / Enero - Junio de 2018

/ ISSN 1794-6670/ Bogotá, D.C., Colombia / pp.43-59

Fecha de recepción: 18 de abril de 2017

Fecha de aceptación: 4 de septiembre de 2017

Disponible en línea: 6 de diciembre de 2017

doi:10.11144/javeriana.mavae13-1.pwrc

* Artículo de reflexión.

* Doctora en Humanidades y Artes con mención en Bellas Artes, Facultad de Humanidades y Artes, Universidad Nacional de Rosario. Posdoctora en Humanidades y Artes por la misma Universidad. Directora del Centro de Estudios Visuales Latinoamericanos, Instituto de Estudios Críticos en Humanidades, Universidad Nacional de Rosario-Consejo Nacional de Investigaciones Científicas y Técnicas. 


\section{Resumen}

Pola Weiss (1947-1990) es considerada una artista emblemática dentro de la videografía mexicana contemporánea. Inauguró una línea de trabajo inusual y de profuso nivel experimental con el uso de cámaras filmadoras. Obras como Videodanza, viva videodanza o Autovideato, de 1979, o Mi co-ra-zón, de 1986, resaltaron la puesta en escena de movimientos libres y osados y estimularon la expansión física en tiempos y espacios singulares. Su obra abrió una serie de interrogantes sobre temáticas que ocuparon a las teóricas feministas. Este trabajo procura trazar algunos señalamientos teóricos a partir de las modalidades con las que Pola exhibe e interpreta los cuerpos. Esos rasgos peculiares se enlazan con los desbordes y las dinámicas que caracterizan los cuerpos presentes en sus videos, donde la materia, los fluidos orgánicos, las emociones y los movimientos físicos se desregulan y perturban las conductas normativas y las convenciones culturales. Para ello, se examinarán documentos originales del Fondo Pola Weiss existente en el Museo Universitario de Arte Contemporáneo de la Universidad Nacional Autónoma de México, en pos de analizar su itinerario artístico. Se considerarán las reflexiones de Rebecca Schneider sobra la performance y las nociones fundamentales sobre la perspectiva de género de Judith Butler, Carol Maier, Laura Mulvey y Nelly Richard. Finalmente, se arribará a una serie de conclusiones que nos permitirán articular los lazos entre la producción de la artista y los conceptos provenientes del feminismo. Más allá de las connotaciones estéticas, se aportará una lectura renovada sobre Pola Weiss al subrayar el potencial crítico de su legado videográfico.

Palabras claves: Pola Weiss; cuerpo; feminismo; videografía

\section{Abstract}

Pola Weiss (1947-1990) is considered an emblematic artist within the contemporary Mexican videography. She inaugurated an unusual line of work and profuse experimental level with the use of camcorders. Works like Videodanza, viva videodanza or Autovideato of 1979 or Mi co-ra-zón of 1986, emphasized the staging of free and daring movements, stimulating the physical expansion in singular times and spaces. Her work opened a series of questions about the themes that occupied feminist theorists. This work tries to draw some theoretical indications from the modalities with which Pola exhibits and interprets the bodies. These peculiar traits are linked to the overflows and dynamics that characterize the bodies present in their videos, where matter, organic fluids, emotions and physical movements are de-regulated, the normative behaviors and cultural conventions are disturbed. For this purpose, I will examine original documents from Fondo Pola Weiss at the University Museum of Contemporary Art of the National Autonomous University of Mexico in order to analyze their artistic itinerary. I will consider Rebecca Schneider's reflections on performance, as well as basic notions on gender perspective posed by Judith Butler, Carol Maier, Laura Mulvey, and Nelly Richard. Lastly, I will draw a number of findings that will allow us to articulate the links between Weiss' production and concepts stemming from feminism. Beyond aesthetic connotations, this work aims at contributing a renewed reading on Pola Weiss by emphasizing the critical potential of her videographic legacy

Keywords: Pola Weiss; body; feminism; videography

\section{Resumo}

Pola Weiss (1947-1990) é considerada uma artista icônica na videografia mexicana contemporânea. Ela inaugurou uma linha de trabalho incomum e de profuso nível experimental com a utilização de câmeras de vídeo. Obras como Viva videodanza videodanza ou Autovideato de 1979 ou Mi co-ra-zón de 1986 enfatizaram a realização de movimentos ousados e livres, estimulando a expansão física em tempos e espaços únicos. Seu trabalho abriu uma série de questões sobre temas que ocuparam teóricas feministas. Este artigo procura traçar algumas discussões teóricas a partir das modalidades com as quais Pola exibe e reinterpreta os corpos. Estas características peculiares estão relacionadas com os transbordamentos e as dinâmicas que caracterizam os corpos presentes nos seus vídeos, onde a matéria, os fluidos orgânicos, emoções e movimentos físicos des-regulam, subvertendo os comportamentos normativos e convenções culturais. Serão examinados documentos originais do Fundo Pola Weiss, que se encontram no Museu Universitário de Arte Contemporânea da Universidade Nacional Autônima do México, para analisar seu itinerário artístico. Também consideraremos as reflexões de Rebecca Scheider sobre performance e noções fundamentais sobre a perspectiva de gênero de Judith Butler, Carol Maier, Laura Mulvey e Nelly Richard. Finalmente será possível chegar a uma série de conclusões que nos permitirão articular os laços entre a produção da artista e os conceitos provenientes do feminismo. Além das conotações estéticas, propõe-se uma leitura renovada sobre Pola Weiss ao sublinhar o potencial crítico de seu legado videográfico.

Palavras-chave: Pola Weiss; corpo; feminismo; videografia 
Los primeros trabajos en videoarte han sido atribuidos a artistas como Nam June Paik o Wolf Vostell. En general, las mujeres que transitaron esa disciplina fueron poco advertidas dentro del campo cultural de entonces. En ese contexto, la mexicana Pola Weiss emprendió un conjunto de experiencias en video que materializaron una obra que obtuvo reconocimiento desde hace unas décadas atrás, gracias a la afanosa tarea de algunas investigadoras. ' Sus tempranas experiencias en formato de video abrieron paso a una serie de trabajos donde la manifestación del cuerpo adoptaría diferentes niveles de intensidad. Pola se graduó en la Facultad de Ciencias Políticas y Sociales de la Universidad Nacional Autónoma de México con la primera tesis escrita sobre video. De paso por Nueva York, se contactó con Nam June Paik y su esposa, Shigeko Kubota, a partir de lo cual comenzó a interesarse con asiduidad en los diferentes procesos del videoarte.

En 1977, realizó La flor cósmica, video exhibido en ese mismo año en el IX Encuentro Internacional de Videoarte y I Encuentro Nacional de Videoarte en el Museo Carrillo Gil organizado por Jorge Glusberg. Las imágenes en blanco y negro se transforman y abren paso a luces amarillentas, violáceas y rosadas que desembocan en la formación de una flor. Las tonalidades viran hacia los amarillos, rojos y azules y remarcan una matriz con connotaciones femeninas, orgánicas y notoriamente sexuales. Pola se embarcó en diversos proyectos y concretó exposiciones y muestras en los Estados Unidos, Venezuela, Francia, Holanda, Uruguay, Polonia, Canadá, Bélgica, Brasil y Argentina. En 1979, exhibió ocho videos en el Centre George Pompidou de París (Francia). Más tarde participó en The Art of Performance, donde filmó Videodanza, viva videodanza. A través de la danza entre espejos, vestida con una malla oscura de baile y medias con botas negras, la artista registraba al público con su cámara al hombro y proyectaba de modo simultáneo las acciones capturadas en un monitor. Durante ese año también concibe Autovideoato, autorretrato en movimiento desarrollado según repetición de su silueta desnuda, con un tratamiento cromático sorprendente, utilizando palabras en inglés y en español.

En 1980, Pola había proyectado mostrar La venusina renace y reforma en el Auditorio Nacional de la Avenida Reforma, pero la presentación se canceló. Decidió concretar, igualmente, su performance y colocó espejos en la calle dejando espacios libres para que la gente pudiese desplazarse y deambular entre ellos. Vestida con una túnica blanca casi transparente y prendas de baile, la artista transitaba el sitio con pasos de danza entre los asistentes. El texto escrito por la escritora argentina Tununa Mercado (por entonces exiliada con su familia en México) para el folleto de La venusina renace y reforma describía esos episodios:

Despliega sus aparatos de videotape y, simultáneamente creadora y creatura —Pola y venusina- de un acto de amor único, recorre y atrapa con su cámara las imágenes y los sonidos que la rodean, las captura en su absoluta momentaneidad mientras danza. No hace una narración del mundo que ve, ni se propone dar una visión de él, sino que lo vive, en un breve espacio de tiempo, con su cuerpo y su cámara. De ese suceso o, más bien, del transcurso de ese suceso, queda un testimonio múltiple: las imágenes, el sonido, su propia danza reflejada en unos espejos; nosotros, el público, parte del acontecimiento, la oscilante y giratoria realidad del mundo y de Pola en el mundo se graban en una secuencia en la que no hay antes ni después, sino puro ser, incisión en un devenir cuya fugacidad, paradójicamente, resume la máxima potencia de la vida, el amor y la muerte. Mujer disparada al espacio por pura obstinación creadora, Pola 
Weiss es un ejemplo de la arrolladora fuerza de la mujer en libertad. Subvierte lo que toca, transgrede lo que roza porque en su desnudez de venusina —ella no es terrícola — abandonada a su último recurso, el de ser artista, se aleja de un arte concebido en y para los escenarios del poder. $^{2}$ (s. f.; figura 1)

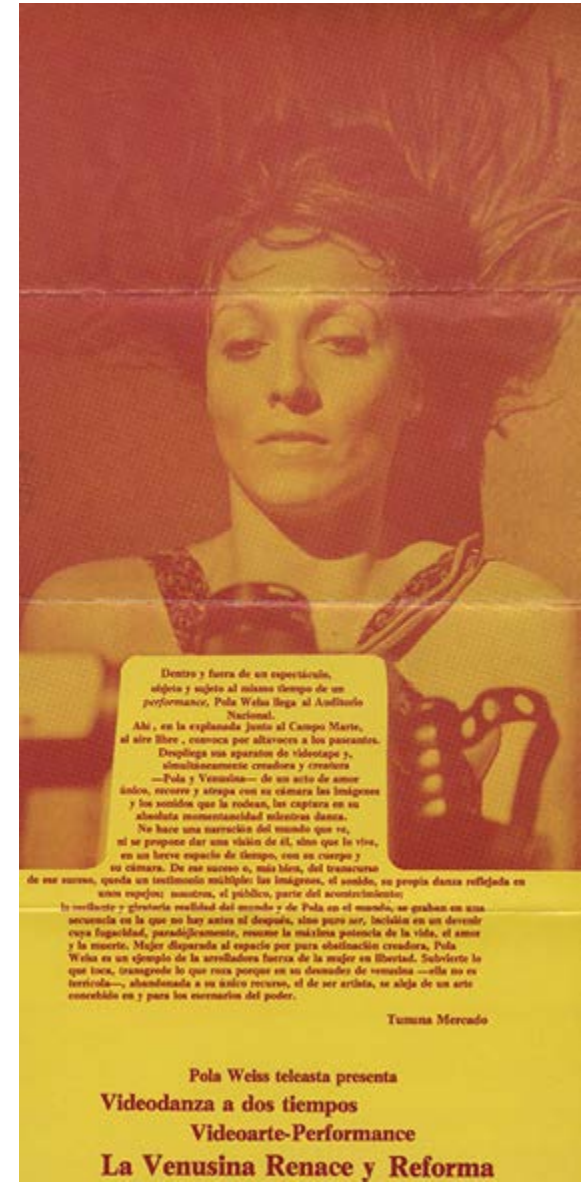

figura 1

Folleto de La venusina renace y reforma, 1980

Fuente: Fondo PolaWeiss, Centro de Archivo y Documentación Arkheia,

Museo Universitario de Arte Contemporáneo, la Universidad Nacional Autónoma de México.

En el transcurso de la Bienal de Venecia de 1984 (en cuyo catálogo se autonombraría videasta y "teleasta"), Pola exhibió videos como Exoego 8, Sol o águila (https://goo.gl/CtVwLN) y Videorigen. Sol o águila, de 1980, fue el resultado de la concatenación de imágenes filmadas sobre las pirámides prehispánicas de Teotihuacán y escenas de la urbe, intercaladas con obras de Jesús Helguera. ${ }^{3}$ En algunos fragmentos, los montajes fluctúan entre las pirámides prehispánicas y los cuerpos representados y abren paralelos y contrastes entre las construcciones aztecas y las obras de Helguera. El pasaje drástico de las manifestaciones arquitectónicas a las representaciones romantizadas desmantela los imaginarios culturales locales: estos discursos cruzados se leen a partir de la confrontación visual entre ambos universos; por un lado, el monumento de piedra que rememora a las comunidades previas a la Conquista; y por otro, los cuerpos construidos a partir de cánones clásicos que, además, fijan estereotipos sexuales (el varón indígena contorneado, fornido, que llevaba en sus brazos a la mujer desvanecida y vulnerable). 
Para adentrarnos en la producción de este video, es necesario revisar algunos detalles del boceto previo. En los manuscritos de Pola, se observan indicaciones, tales como "plano general de Teotihuacán", "pirámide de la luna" y "grandeza azteca", con las cuales se refiere a la pintura de Jesús Helguera mencionada. Se ve el dibujo de la "pirámide de la luna", el "gesto azteca", la "calzada de los muertos" (zona característica de este conjunto arquitectónico), "Ios volcanes", "flechador" (protagonista de otro de los óleos de Helguera) y "amor indio" (en relación con la pareja) (figura 2).

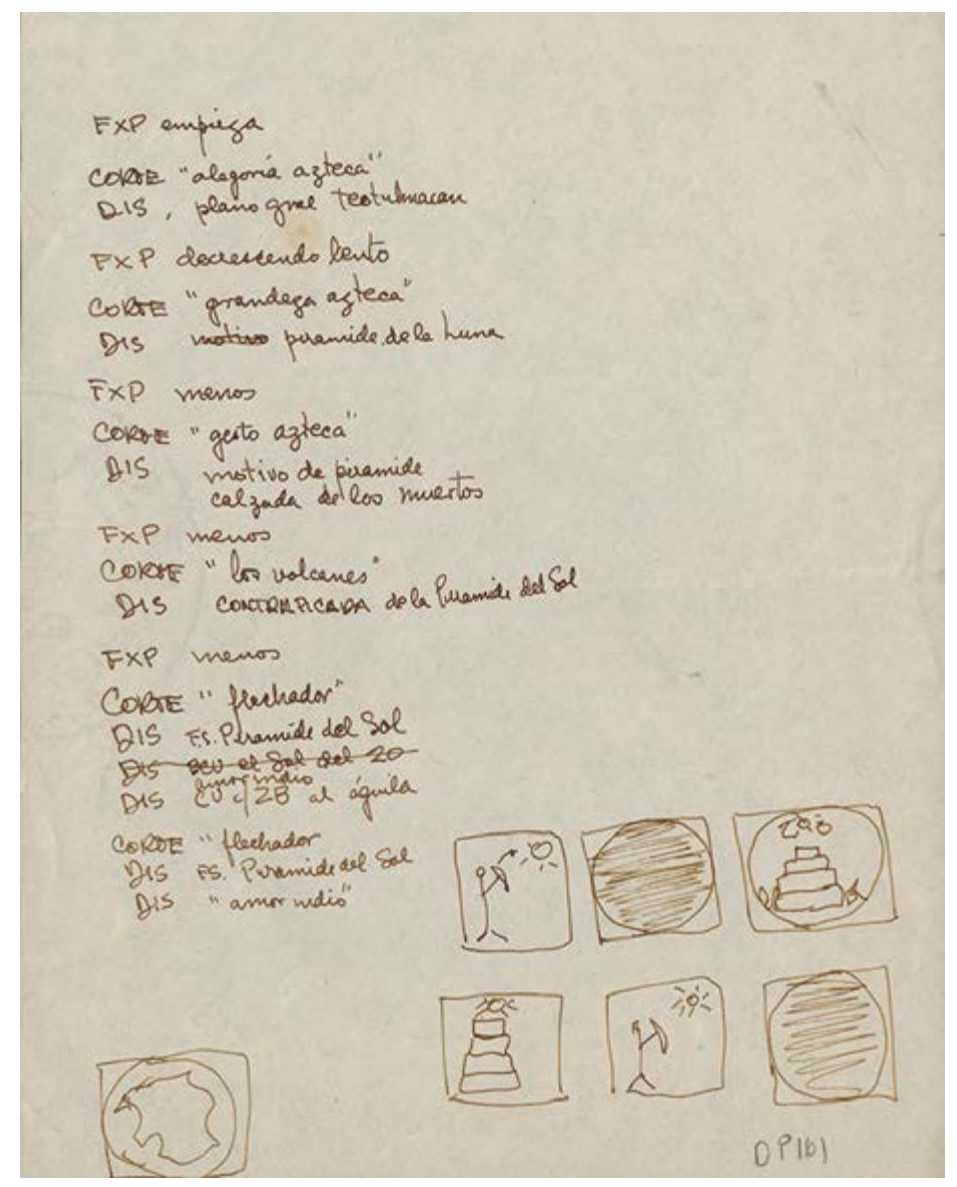

figura 2

Manuscrito Los conceptos espaciales son la acción interiorizada, s. f.

Fuente: Fondo Pola Weiss, Centro de Archivo y Documentación Arkheia,

Museo Universitario de Arte Contemporáneo, Universidad Nacional Autónoma de México.

En otros gráficos, pueden leerse instrucciones sobre cómo y dónde filmar, "Teotihuacán antes de que amanezca, plano general, tonalidad café, con sus colores atenuados", o referencias a la incorporación de monedas en la transición de un fotograma a otro. Pola estableció que esas monedas debían ser de veinte centavos con un sol. Cuando una de ellas girase en el aire, la cámara se enfocaría en el águila. También menciona los edificios de la Ciudad de México, un "teporocho" (borracho humilde) parado y a un "tipo" sentado. En lo que respecta a las resoluciones técnicas del video, según sus indicaciones, los primeros planos se desvanecían para dar paso a las nuevas formas. La inclusión de la moneda (con fecha de 1974) se reitera y adopta tonalidades magentas, girando sobre sí misma y, en ocasiones, funcionando como un sol en cada toma. 
El óleo de Jesús Helguera titulado La leyenda de los volcanes I/ o Grandeza azteca de 1943 constituye una de las referencias más conocidas de Sol o águila. Vemos a un azteca ornamentado con plumas y atuendo de colores que mira hacia lo lejos y lleva en sus brazos a quien sería la encarnación femenina de un volcán, dormida y en reposo. La versión exotizada del indígena que plantea Helguera se refleja en la fémina frágil que es transportada por él mismo, antes de mutar en una formación geológica ígnea que irrumpirá como lava volcánica. Dicha imagen connota un sesgo patriarcal que exacerba la dicotomía masculino/femenino. El patriarcado, como esquema dominante de valores, postula la supremacía masculina que en este caso aparece encarnada en la figura de un hombre robusto y enérgico. Francesca Gargallo (2004) ha señalado la vinculación de esa dualidad con pares tradicionales que jerarquizan un componente sobre otro, como mente-cuerpo, racional-emocional, abstracto-concreto, identidad-alteridad, etc. Al quitarles sentido y valor cognoscitivo a las características relacionadas con lo femenino, es asegurada la perdurabilidad de esa lógica dicotómica (91). El modelo patriarcal se ha fundamentado muchas veces en premisas de corte biologicista, según las cuales el rol tradicional de la mujer es constituyente del código genético, por lo cual el "determinismo biológico se convierte en una obligación, en realidad una defensa política del statu quo en lenguaje científico" (Lerner 1990, 40). ${ }^{4}$

Luego del dúo de figuras que reflejan estos estereotipos, Pola incluye en su video la presencia de hombres y mujeres indigentes e imprime una nueva dimensión temporal y política a la problemática social mexicana. Un sujeto vagabundea por las calles de la ciudad, sin rumbo y desaliñado, con sus cabellos revueltos. Los registros de gente humilde refieren a la miseria citadina y desembocan en un cartel con la palabra salida. Su intención de incorporar a los protagonistas desarraigados de la sociedad, como el "teporocho" o los demás indigentes, demuestra su preocupación por los sujetos excluidos y por establecer contrapuntos entre la remembranza icónica e histórica y la realidad actualizada. El recurso de las monedas se repite en un paisaje de colores anaranjados y funciona como un objeto volador, parasitario, en medio del círculo que enmarca sobre el fondo negro, tal como finalizan algunas películas de cine.

En 1981, Pola produjo el video Ciudad mujer, filmación en la que se superponen tres planos básicos en interacción: la irrupción de formas coloreadas con tonos intensos que se van transformando, los registros de la metrópolis caracterizados por el vértigo constante y los movimientos enérgicos de una bailarina que se sacude de manera ininterrumpida, acorde con la melodía que se escucha de fondo o las exclamaciones de la voz en off (emitidas por la misma Pola). En el inicio, las configuraciones geométricas de fuertes colores dan paso a panorámicas de montañas y zonas urbanas mexicanas; se escucha el canto de los pájaros. Los colores se acentúan y aparece desnuda en el suelo Vivian Blackmore, protagonista del video. En la ciudad, los habitantes se suben a los buses, caminan, pasean y corren, mientras los planos de color se metamorfosean y el cuerpo femenino se despierta, se despereza y moviliza. En las tomas donde vemos agua, surge la voz de Pola: "No hay agua, tengo seca la boca [...] porque lloro cuando río [...] y me sale agua de por dentro, desde mi cuerpo, han bloqueado todos los ríos, teníamos tanta agua que sobraba", todas frases que revelan la analogía entre la silueta de la mujer y la topografía citadina; las emociones femeninas se corresponden con sucesos en la geografía local y la corporeidad encarna la urbe. Los movimientos de la mujer sugieren libertad, sexualidad en su desnudez, soltura, goce y deleite en el ejercicio físico. Son acciones moduladas con curvas y contracurvas, donde la bailarina se expresa de manera espontánea en cada uno de los planos. Su silueta de tonalidad carne contrasta con los colores efusivos 
e iridiscentes del fondo (amarillo limón, verde, rosa claro y azulados) a través de una danza seductora donde el cuerpo se contorsiona mediante gestos sinuosos, eróticos y catárticos.

Autos que viajan por las calles, tramas grisáceas, edificaciones, terrazas desde el aire y cúpulas. Dice Pola: "No hay aire tampoco, se me ha secado la voz, y el aliento se me corta, cuánto ruido, cuántos autos, cuánto humo, todo es gris y lleno de basura que no me deja respirar." Aquí la melodía de fondo adopta otro tono, se dinamiza, acelera y suenan tambores, hay referencias a la prisa, el caos diario y el ahogo, "todos corren como si estuvieran solos, deténganse, véanme, escúchenme [...] por qué no me dejan ser [...] tiempo detente, quiero vivir". El pubis femenino se colorea con tonalidades brillantes como resultado de los experimentos ópticos y lumínicos de la artista. La sexualidad manifiesta en los órganos femeninos que se ven en primer plano adquiere preeminencia en relación con el resto de las imágenes que componen la filmación, y en un punto se disuelven sus contornos hasta fundirse con planos cromáticos y luces lejanas. Es de noche, y el cuerpo de Vivian yace tendido. Posteriormente, la cámara se enfoca en su ombligo y, al alejarse, la bailarina se ha colocado en posición en cruz. A grandes rasgos, el despliegue de imágenes en Ciudad mujer se caracteriza por la inclusión de tonos intensos y contrastados, con una sumatoria de datos gráficos que subrayan la relación entre el cuerpo y la ciudad.

Durante 1985 se desencadenó un feroz terremoto en la Ciudad de México que devastó la cartografía urbana y el ámbito social de modo catastrófico. A partir de esa temática, Pola realizó Mi co-ra-zón. El video se inscribe en la similitud entre el movimiento sísmico real y la convulsión interna de la autora en relación con la pérdida de su bebé. Escuchamos latidos de un corazón vivo, y surgen referencias a la menstruación en la flor que gotea sangre. Pola se retuerce, baila y parpadea, tras lo cual su figura adquiere un tinte verdoso. Destellos de un electrocardiograma y lágrimas cristalinas. Se establece una analogía entre su figura embarazada y la pintura de Gustav Klimt titulada Esperanza I, de 1903. Pola ingresa al hospital, la palabra feto está escrita en una calavera. El imaginario personal de la artista se cruza con escenas del terremoto en México, se derrumban estanterías, paredes, mazos de cartas, sobrevienen imágenes de torres que se desploman y emerge la palabra México. Pola en cuclillas, los enfermeros que socorren, las ambulancias que suenan y la gente que auxilia a quienes quedaron atrapados bajo las piedras. Desastre, roturas y cables caídos. Pola, desnuda, se despereza y baila sobre un fondo de la ciudad en ruinas. Se solapan los fragmentos de otro cuadro de Klimt, La vida y la muerte, de 1911. El espectro de una calavera con guadaña anuncia la muerte. La artista se coloca en posición de $V$, hacia abajo, con un fondo de corazón rojo y vivo, que late. El cuerpo de Pola colapsa, lo cual sugiere la muerte de su niño por el aborto espontáneo. El doloroso episodio fue resignificado en una producción visualmente disruptiva en relación con las formas narrativas más convencionales sobre la imagen en movimiento (Lucero 2014, 7).

Según Ángel Mercado (s. f.), quien en el catálogo de presentación definió Mi co-ra-zón como "videoarte de la tragedia", una de las visiones que los distintos artistas han manifestado sobre el terremoto de México, y que constituyeron evidencias de valor histórico, donde la tragedia operó como un disparador para activar la obra misma. En el trabajo de Pola, la visualidad desplegada tensiona los elementos constitutivos del lenguaje plástico con una semántica de aflicción y muerte en la que incluía su propia experiencia: 
Ver y sentir los latidos de la ciudad es un privilegio que puede durar unos segundos o muchos años. Tiempo de danza que reclama sus protagonistas. Así, una mujer envuelta en velos multicolores, aparece en el óvalo de la televisión bailando con extrema lentitud, al ritmo, diríase, del agua que reposa en Xochimilco o la vieja Tenochtitlán. Tac tac tac. Música monótona marcada por los siglos, al fin que la cita es en la ciudad de México a las 7:19 horas del 19 de septiembre de $1985 .^{5}$ (Mercado, s. f.; figura 3)

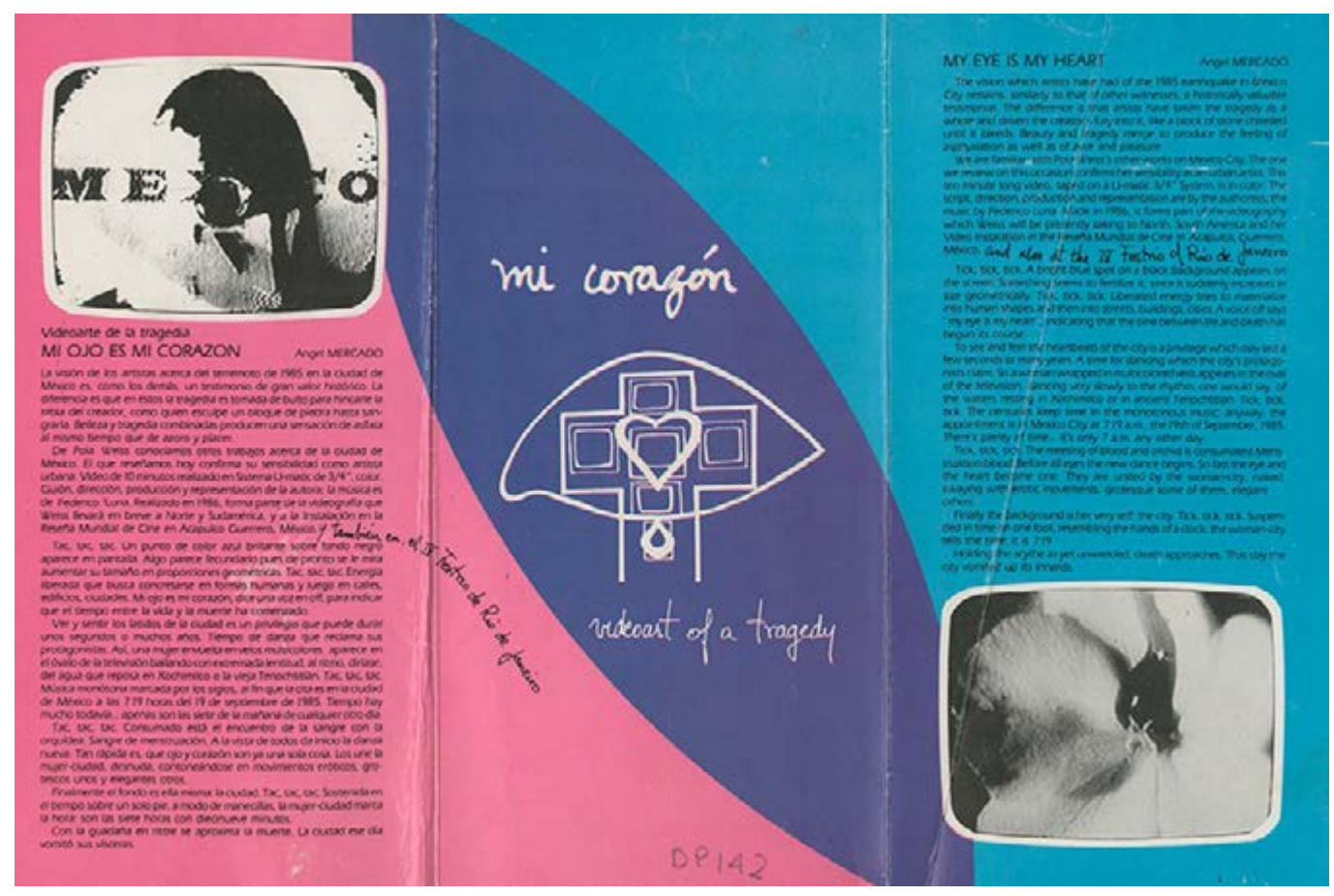

figura 3

Folleto de Mi co-ra-zón, 1985

Fuente: Fondo Pola Weiss, Centro de Archivo y Documentación Arkheia,

Museo Universitario de Arte Contemporáneo, Universidad Nacional Autónoma de México.

A la par de una experimentación vertiginosa, Pola rehabilitó un tópico tabú, como el aborto, al exponerlo públicamente, superponiendo la catástrofe de 1985 en México con una coyuntura íntima. Existe un registro de especificaciones y un gráfico, fechado en 1987, donde la artista detalló los elementos técnicos necesarios para el video: una estructura de metal (rack) de $2 \mathrm{~m} \times 2.50 \mathrm{~m}$ en forma de cruz; un panel en forma de trapecio de tres costados de $5 \mathrm{~m}$ de fondo por $3.20 \mathrm{~m}$ de altura; dos piezas de luz de neón en forma de ojo de $4 \mathrm{~m} \times 2.5 \mathrm{~m}$ de color verde; una pieza de luz de neón en forma de corazón de $1 \mathrm{~m} \times 1.15 \mathrm{~m}$ de color rojo; una pieza de luz de neón en forma de cruz de $2.3 \mathrm{~m} \times 2.7 \mathrm{~m}$ de color blanco; una pieza de luz de neón en forma de lágrima de $35 \mathrm{~cm} \times 40 \mathrm{~cm}$ de color azul; un monitor color de 25"; un monitor color de 13"; cuatro monitores colores de 19"; una videocasetera VHS de $1 / 2$ "; y cables blancos de interconexión. ${ }^{6}$ El criterio minucioso con que organizaba sus instalaciones revela su experticia sobre los aspectos tecnológicos del video, en un momento del arte mexicano donde sus trabajos resultaban desconocidos para el público, especializado o en general. 
Los atlantes, de 1989, es uno de los proyectos de Pola menos conocidos. Se trata de una "video-instalación-olfativa", tal como ella lo denominó. Según sus documentos escritos,

el tema es la historia de la Atlántida, video de 13 min de duración con tomas subacuáticas. Es una gran pecera de verdad con los monitores dentro. La estructura será toda de acrílico por la transparencia. La pecera es redonda con un monitor de 27", atrás son 8 monitores: 1 de 27",

7 de 21 ." Los Atlantes estarán emitiendo olor a mar y coco de manera intermitente. (figura 4)

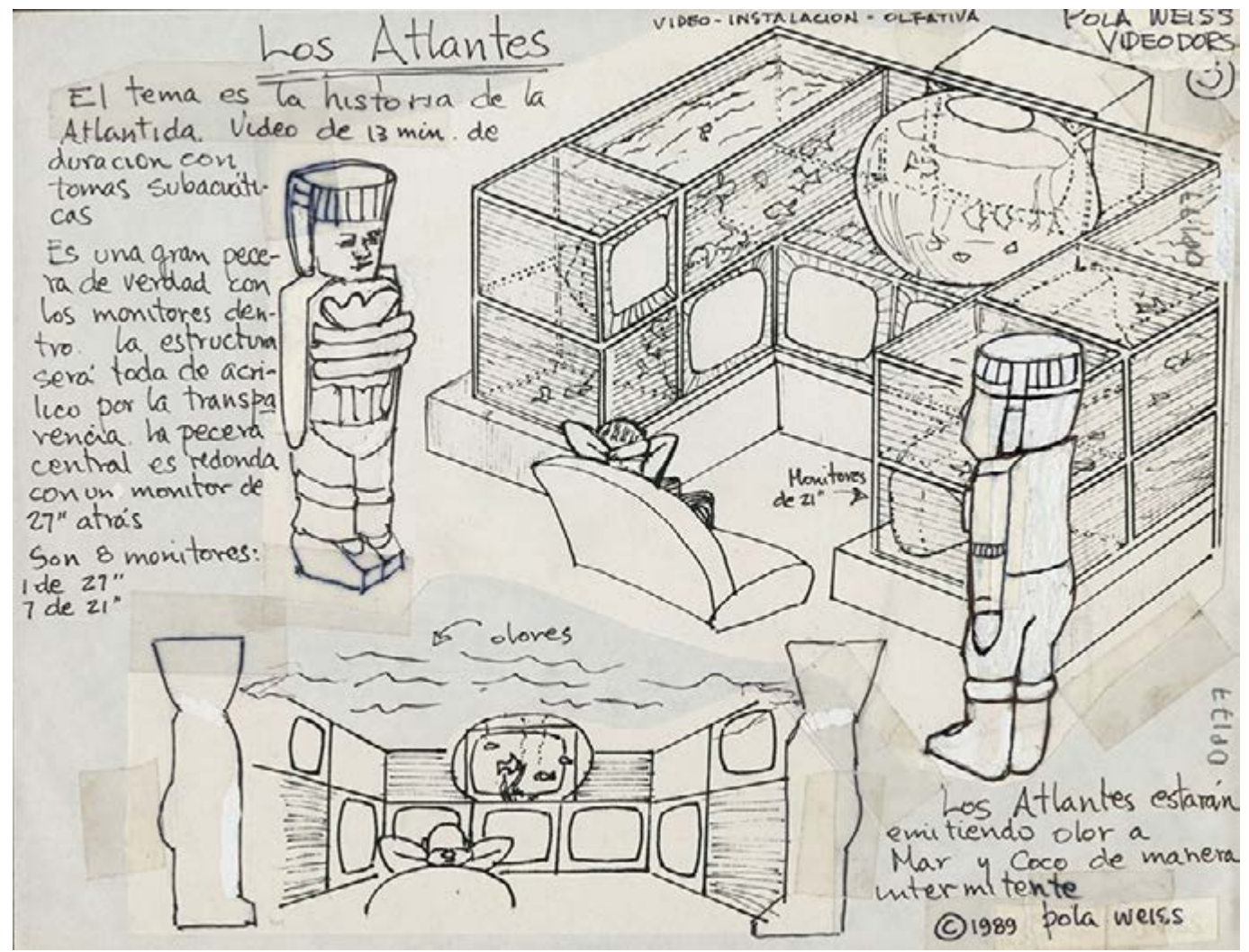

figura 4

Boceto preliminar del proyecto Los atlantes, 1989

Fuente: Fondo Pola Weiss, Centro de Archivo y Documentación Arkheia,

Museo Universitario de Arte Contemporáneo, Universidad Nacional Autónoma de México.

La introducción del sentido olfativo en las vivencias del espectador a partir de la emanación de ciertos olores, en este caso el aroma del mar y del coco, generan nuevas dimensiones perceptivas, otro tipo de estímulos sensitivos en el espectador. Al recuperar a los atlantes las enormes esculturas de Tula en el estado de Hidalgo (México), se instituye un diálogo con el pasado que se reactualiza en una construcción artística contemporánea bajo la impronta tecnológica. La posible historia acerca de la Atlántida también nos acerca a una dimensión utópica enlazada con la búsqueda de respuestas sobre la condición humana. En los gráficos, se observan las figuras de pie en la antesala de lo que sería la instalación completa que intercambian los aromas de cabeza a cabeza, en posición de recibir al observador que va a sentarse en un sillón colocado en el medio para contemplar las pantallas en funcionamiento. En el caso del 
monitor central, este se encuentra detrás de la pecera, posición que origina efectos particulares, ya que las luces emitidas por los rayos de cada televisor se filtrarían entre los peces que nadan. En los laterales, los monitores se localizan al lado de las cajas cristalinas con peces.

Posiblemente, este proyecto haya quedado sin concluir, puesto que fue bocetado un año antes de la muerte de Pola. La intencionalidad de comunicar ideas y conceptos integradores en la vivencia física del espectador ante este tipo de obras refuerza la hipótesis sobre el perfil experimentador y rupturista de Pola Weiss en el México de la década de 1980. Tanto en la producción de videos como en la concepción de obras multisensoriales que involucran el espacio en su totalidad, su itinerario artístico impulsó una estética arriesgada, comprendida, estudiada y valorada varias décadas más tarde. ${ }^{8}$

III

Si bien Pola no se manifestó abiertamente como una feminista activa, accedía a lecturas en relación con este proyecto social y político. Tenía en su archivo personal publicaciones como Des femmes en mouvements hebdo, revista editada en Bilbao en 1979. ${ }^{9}$ En el suplemento del número 1 (en cuyo índice figuraba el artículo "Du féminisme paternaliste et colonialiste"), se veía en primera plana la fotografía de un grupo de mujeres que portaban una tela con la leyenda "Amnistía para las 11 mujeres, derecho al aborto." Tanto en Ciudad mujer como en Mi co-ra-zón plantea correlatos entre el cuerpo femenino y la cartografía mexicana a través de sentimientos, ideas y emociones personales que exponen visiones documentales y composiciones estéticas acerca del aborto (en este caso no deseado) y adoptan una modalidad de intervención pública al asumir una posición sobre el tema (figura 5).

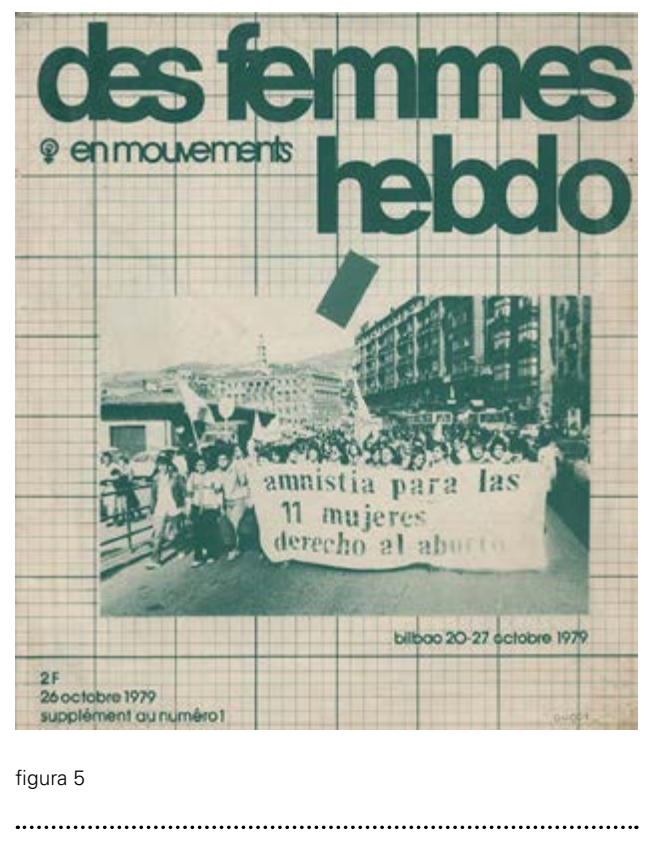

Suplemento cultural Des femmes en mouvements hebdo, Bilbao 2027 de octubre 1979, 2 F 26 octubre 1979, supplément au numéro 1. Fuente: Fondo Pola Weiss, Centro de Archivo y Documentación Arkheia. Museo Universitario de Arte Contemporáneo, Universidad Nacional Autónoma de México. 
En general, toda la obra de Pola Weiss abrió una serie de interrogantes sobre temáticas que ocuparon a las teóricas feministas. Hay algunos señalamientos sobre cómo la artista presenta a los cuerpos que es preciso analizar. Esas particularidades se enlazan con las dinámicas que caracterizan a los cuerpos en sus videos, donde emergen cuerpos desregulados que se desmarcan de la norma y de las convenciones. Sin adentrarse en el terreno de las distintas sexualidades o de los cuerpos admitidos o no, el imaginario cultural/corporal que cruza estos videos es difícil de encasillar. El abordaje de Judith Butler en relación con cuáles son los "cuerpos que importan" al discurso hegemónico (y cuáles se descartan) podría acercar algunas herramientas que permitirán leer las modalidades corporales en estas experiencias fílmicas desde un ángulo distinto. Butler propone varias cuestiones para ser reenunciadas en relación con la materialidad de los cuerpos, entre ellas, la reconsideración de la materia de los cuerpos que resulta de una determinada dinámica de poder o la vinculación del mecanismo de asumir un sexo con la caracterización de medios discursivos heterosexuales. Estos procesos entrañan la presencia de un parámetro excluyente de lo abyecto que expulsa a ciertos sujetos de la vida social a la invisibilidad $(2011,58-59)$. Respecto de las posibilidades de construcción de lo sexual, la autora formula el retorno a la noción de materia como una perspectiva de materialización que se consolida en el tiempo para dar lugar a lo que denomina efecto de frontera o de permanencia. Cada construcción es en sí misma su teatralidad, ejecutada en el acto presente. La materialización se lleva a cabo en la sedimentación de estos procesos y en el acopio de las citas repetidas.

La complejidad del pensamiento de Butler nos conduce a reflexionar sobre los regímenes sexuales que regulan el comportamiento social y que estipulan cuáles cuerpos son los que importan y cuáles no, tras lo cual quedan estos últimos relegados a la esfera de la abyección. Por tanto, lo confinado y excluido puede retornar de manera perturbadora. Volviendo al cuerpo que filma (y se filma) Pola: pensemos que la recurrencia a la desnudez, las secreciones (el flujo menstrual), la contorsión y la descontracción van forjando un lenguaje corporal que nos remite a áreas somáticas reprimidas o silenciadas que evocan aquello que puede provocar repulsión o rechazo.

Por otro lado, estos videos exploran las posibilidades de cortes o restos a partir de montajes que operan como documentos de la actividad misma que se despliega en tiempo real, coincidente con la duración del video. Tanto las acciones que se desarrollan en las filmaciones como las mismas presentaciones de Pola en público asumen la categoría de performance, término que desde el discurso de varios autores se relaciona con la desaparición por su carácter efímero. Rebecca Schneider nos aporta una nueva perspectiva y define la performance como algo que permanece (como constitutivo del acto mismo de permanecer) y que persiste justamente en los archivos que se han generado sobre la propia acción. Schneider se refiere a la puesta en acto real donde el cuerpo sobreviene en archivo de una memoria colectiva y los significados "espectrales" de la performance resurgen en una continuada interacción colectiva: "Lo corporal, leído a través de generaciones de impacto que quizás son siempre performativas" $(2011,232)$. En los desplazamientos corporales desplegados en los videos de Pola, encontramos una cantidad importante de fragmentos que remiten a las acciones corporales per se.

En Mi co-ra-zón, observamos su ojo en primer plano, el corazón vivo que late, la bailarina desnuda, el embarazo remarcado en la figura femenina de Klimt, su ingreso al hospital, el terremoto, recortes que componen una secuencia archivística que funciona como testimonio visual de los actos y alternan con ellos. Esta secuencia de impactos visuales resignifica los archivos visuales-icónicos al potenciar movimientos de carácter 
performático en los cuerpos dinámicos. En la videografía de Pola, las posturas corporales traducen ideas, sentimientos, emociones y pensamientos y configuran un lenguaje visual potente. El abordaje que plantea Carol Maier sobre la traducción en el feminismo nos permite pensar el cuerpo como narración y como constitutivo de un texto "que la mujer teme, pero que también desea leer, aunque esté negando su textualidad" $(2008,43)$. A partir del análisis de algunos escritos de la feminista chilena Amanda Lamarca, Maier sostiene que el cuerpo femenino posee señales que deben ser reconocidas para desde ahí emprender una lectura del cuerpo como un texto. La noción de textualidad femenina es potencialmente operativa para revisar una obra compleja y a su vez poderosa, como la de Pola Weiss, ya que tanto en la antesala de los proyectos como en el despliegue de estos convergen significados y percepciones de lo corpóreo que exceden los binarismos y las lecturas simplificadas. Afirmaciones y negaciones, desnudez y ocultamiento, apertura y cierre, color y acromatismo. Todas estas opciones se tensionan con el ritmo y la cadencia que le imprimen tanto el movimiento como la música a cada filmación, en un entramado de imágenes que es en sí mismo sinuoso, incesante y visceral.

\section{IV}

Registros videográficos de cuerpos en movimiento que dialogan con los desbordes de la materia real. La visibilidad del cuerpo femenino en la narrativa cinematográfica ha sido analizada con lucidez en 1975 por la teórica Laura Mulvey, quien reflexiona sobre la mirada del sujeto masculino, su placer voyeur frente a la objetivación del cuerpo femenino y las estructuras que influyen en esos modos de ver. La injerencia del falocentrismo ha irradiado cánones culturales que colocan el falo como eje y centro de las prácticas sexuales. El peso de las teorías freudianas colaboraría con esta herencia al identificar a la mujer en relación con la carencia de pene o falo, por lo cual su estructura psicológica "supuestamente se centraba en la lucha por compensar dicha deficiencia" (Lerner 1990, 39). Este enfoque provocó la necesidad de fundar la figura femenina como oprimida o castrada, la que subsiste como el "significante del otro masculino, ligado por un orden simbólico en el que el hombre puede experimentar sus fantasías y obsesiones mediante el orden lingüístico al imponerlas en la imagen silenciosa de la mujer aún atada a su lugar como portadora, no creadora, de significado" (Mulvey 2007, 82). El medio cinematográfico y las imágenes en tránsito nos plantean cuestionamientos sobre las maneras en que observamos y decodificamos lo visual, condiciones que están regidas por patrones culturales normativos. La autora ha subrayado la trama de modelos que impulsan la lectura de lo placentero (respecto del erotismo) en el cine y la posición que ocupa en ese entramado la figura femenina.

Como estrategia de análisis, Mulvey distingue entre dos regímenes de la mirada. En primer lugar, la escopofilia, o sea, el placer de ver que procede a colocar al otro como objeto; y en segundo lugar, la relacionada con la conformación del ego que deviene identificación con lo observado. Por tanto, "en términos fílmicos, una supone una separación de la identidad erótica entre el sujeto y el objeto en la pantalla (escopofilia activa), la otra exige la identificación del 
ego con el objeto de la pantalla por medio de la fascinación del espectador con este y el reconocimiento de su semejanza" (85). Si en la primera sopesan los instintos sexuales, la segunda implica la libido del ego. Dentro del psicoanálisis, Freud comprendió ambas dimensiones como disposiciones formativas en interacción que estimulan una fantasmagoría erotizada, aspecto visible en el mundo del cine (donde se tensionan libido y ego). A partir de estos postulados, Mulvey considera que en el placer de ver se establecen dicotomías tales como activo-masculino y pasivo-femenino, donde el componente masculino ensaya su mirada hacia el cuerpo femenino y lo convierte en su fantasía. La mujer asumiría el rol de objeto sexual que atrae las miradas y otorgará significados y motivaciones al ver masculino; por tanto, ella, como imagen, adquiere sentido de pasividad e inmovilidad. Por el contrario, el varón está excluido de la cosificación sexual, ya que ejerce el control sobre la fantasía femenina que proporciona la imagen en movimiento y es el portador de la mirada que objetualiza. Más allá de estas observaciones, la imagen femenina, la mujer como ícono "exhibida para la mirada y el disfrute del hombre, el controlador activo de la mirada, siempre amenaza con evocar la ansiedad que significó originariamente" (88), tanto en el voyerismo que controla y subyuga como en la fetichización visual de la alteridad femenina.

Desde este enfoque, la visión artística de Pola Weiss, traducida en el modo en que ha concebido sus videos, produce una ruptura con la escopofilia identificada por Mulvey en sus dos vertientes, por diversas razones:

1. En primer lugar, si tomamos dos ejemplos sobre la presentación de los cuerpos femeninos, o bien se contorsionan exhibiendo sin censura el pubis con la voz de Pola de fondo e intersectando colores y formas dinámicas como en Ciudad mujer, o bien traducen dolor como en Mi co-ra-zón en relación con el feto perdido, con acercamientos a la mirada de la protagonista que muestran las lágrimas (símbolo de vulnerabilidad) convertidas en piedras, lo cual perturba la imagen de lo femenino como fuente de placer visual. Asimismo, las superposiciones de los cuerpos, que generan movimientos sugerentes o sexuales danzando sobre vistas panorámicas o sobre episodios de la catástrofe mexicana, no toleran una lectura de tipo voyerística, ya que ese trasfondo dramático y caótico desmonta el sentido frecuente adjudicado a la observación de la desnudez vinculada al erotismo. De este modo, Pola en su filmación desplaza el sitio común de la mujer-fetiche, que incluye imágenes que sobresaltan al espectador.

2. Sus videos transmiten mensajes contundentes que bordean un imaginario feminista a partir de cimentar y constituir la obra sólida de una mujer-artista, con libertad, no solo de elegir sus propios argumentos videográficos, sino de materializarlos con técnicas elegidas y elaboradas por ella misma.

3. La intensidad, profundidad y tenacidad presente en la experimentación visual de Pola Weiss destaca su producción de la de sus contemporáneos: por los ensayos en relación con la imagen en movimiento (mezclas ópticas, colores y formas), por el agregado de aromas en las instalaciones con pantallas (aspecto inusual para los desarrollos con nuevos medios tecnológicos de aquel entonces) y por su mirada genuina en relación con pautas estéticas pensadas desde la perspectiva de género. 
Para ampliar esta perspectiva, y los criterios artísticos que conlleva, es necesario recapitular algunas reflexiones sobre el género. Nelly Richard nos recuerda que el término se vincula a un principio de identificación o tipificación y se referencia en un sistema clasificatorio general. El feminismo, justamente, intenta desmontar esas normas regulatorias al afirmar que las tipologías sexuales no equivalen a los rasgos biológicos de los cuerpos de "hombres" y "mujeres" o a los roles designados en el común de la sociedad. Los cuestionamientos de los cánones que imprimen el binarismo masculino/femenino se apoyan en la complejidad de los procesos sociales y en el análisis de las mediaciones culturales que inciden sobre estas categorizaciones. Por eso, el concepto de género resulta eficaz en cuanto "visibiliza teóricamente el corte entre naturaleza (cuerpo sexuado) y cultura (construcción social de la diferencia sexual) para convertir esta separación en un sitio de intervención conceptual y de transformación política de lo "femenino" que se opone al determinismo biológico" (Richard 2008, 95). De ahí la existencia de una ideología de géneros, la cual se refiere, según la autora, a una construcción ideológica que establece una línea demarcatoria entre lo masculino y lo femenino, y que destina a lo intangible o indiferenciado a la mujer misma. ${ }^{10}$ Ello desemboca en una tendencia a concebir lo público como una dimensión universal, colectiva y masculina, y la privacidad como doméstica y femenina, aspecto que el enfoque feminista procura problematizar. Estas reformulaciones teóricas permiten al feminismo deliberar sobre las microprácticas de la cotidianidad que, en definitiva, impregnan los modos de pensar en comunidad (hecho que se traduce en la recordada frase de la feminista Kate Millet en la década de 1960: lo personal es político).

Judith Butler discute si el género es la construcción social del sexo dentro de una determinada cultura y se pregunta si este consiste en las significaciones sociales que asume el sexo, entonces "el sexo no acumula pues significaciones como propiedades sociales adictivas sino que más bien queda reemplazado por las significaciones sociales que acepta; en el curso de esta asunción, el sexo queda desplazado y emerge el género" (2011, 62). Butler propone trascender los procedimientos deterministas meramente constructivistas y para ello apela a la materia como efecto productivo, tal como mencionamos.

El itinerario poético de Pola que se destaca en su videografía de la década de 1980 altera las clasificaciones habituales sobre las generalizaciones sexo-genéricas. Portadoras de un caudal de emociones intensas que las llevan a ejecutar movimientos incesantes y agitados, las féminas que protagonizan las filmaciones (Vivian y la misma Pola) bailan y se deslizan con libertad, despojo, sin pudores ni censura. En las escenas, se emiten crónicas desgarradoras de diversas tragedias ("no hay agua, tengo seca la boca", "han bloqueado todos los ríos, teníamos tanta agua que sobraba") o se reanudan sucesos fatídicos (la muerte colectiva y el aborto de la artista) que sostienen una narrativa incómoda y perturbadora y dislocan el correlato de lo femenino con la intimidad disciplinada, la mansedumbre o la docilidad. Los desbordes - derramamientos, signos de abundancia e incremento de las capacidades sensitivas-que emergen en el plano visual son del orden corporal, flujos, líquidos, sangre, lágrimas, pieles y vellos públicos; este conjunto denota una visión particular del sexo que torna legítima una mirada sobre su obra en clave feminista. 
A modo de cierre. Pola Weiss ha forjado un modo personal de iniciar y finalizar sus videos. Tanto en Sol o águila como en Mi co-ra-zón (y muchos otros) observamos una elección estética que se reitera y que alude a la idea de un comienzo pautado por el uso de ciertas formas, cuerpos, objetos y efectos lumínicos, con un cierre que es en sí mismo un retorno al inicio, una vuelta al origen y un giro urubórico. La riqueza de temas que se entraman en su producción prefigura el cuerpo femenino como eje de referencia. Quizá en cada lectura encontremos un concepto nuevo, un argumento diferente. Pensemos que los debates que ha instaurado el feminismo (sobre cuestiones de género, el rol de la mujer, los sistemas jerárquicos, la opresión generada a partir de las dicotomías de valores o el esquema patriarcal) tienen una visibilidad creciente en la cultura contemporánea. Tal amplitud de horizontes torna al feminismo "una forma de ver y analizar el mundo tomando en cuenta la primaría de las relaciones de género como relaciones de poder, que estructuran tanto aspectos 'objetivos' como 'subjetivos' de la realidad social y cultural, así como la conciencia y la vivencia corporal y psicológica" (Cordero y Sáenz 2007, 7). Desde esa perspectiva, podemos concluir que Pola Weiss ha transparentado una manera inteligente y aguda de abordar algunos de estos dilemas a partir de las diferentes modalidades de configurar y organizar la visibilidad del cuerpo femenino. En gran parte de su obra, inscrita en la década de 1980, las acciones corporales se abren a la profusión de movimientos y al desborde productivo donde la piel y el sexo confrontan al espectador. De ahí que esas imágenes, desafiantes, arriesgadas y disidentes dentro del ámbito mexicano, cobren actualidad al activar zonas inexploradas y al transitar las problemáticas de género que atraviesan el pensamiento feminista.

\section{NOTAS}

1 Destaco el trabajo de la investigadora mexicana Edna Torres Ramos. En Pola Weiss: re-conocimiento (2012), menciona su labor sobre el acervo documental de la artista, radicado actualmente en el Museo Universitario de Arte Contemporáneo de la Universidad Nacional Autónoma de México bajo la denominación Fondo Pola Weiss, el cual he consultado para el este artículo. Agradezco la buena predisposición y cordialidad de Pilar García y Sol Henaro.

2 Según consta en el impreso. Crédito: Fondo Pola Weiss, Centro de Archivo y Documentación Arkheia, DP 152, Museo Universitario de Arte Contemporáneo de la Universidad Nacional Autónoma de México.

3 En la década de 1980, surgía en México un grupo de artistas que fueron agrupados en torno al llamado neomexicanismo, entre ellos, Enrique Guzmán, Julio Galán o Javier de la Garza. A partir de una iconografía constituida por símbolos nacionales elaborados desde una perspectiva irónica o satírica, estos pintores instalaron un programa estético, cuyo sostén era el cuerpo erotizado, transgredido y homosexual. Teresa del Conde, en un artículo titulado “Nuevos mexicanismos", ha citado como precedente de la renovación neomexicanista una zona de la producción visual nacional que incluye a Jesús Helguera. Sin embargo, en su artículo, se soslayaron las distancias conceptuales y reflexivas entre la obra de Helguera y los llamados neomexicanistas. Las diferencias son notables, dada la mirada crítica de estos últimos en relación con los estereotipos nacionales sobre el nacionalismo mexicano (Debroise 2007, 318). 
4 Rita Segato anexa la noción de colonialidad de género a la existencia del patriarcado visible en ciertos pueblos nativos. Al reflexionar sobre las organizaciones patriarcales en las sociedades indígenas y afroamericanas, la autora advierte la existencia de un "patriarcado de baja intensidad" que se distancia de la construcción occidental generalizada, y que incluye prácticas transgenéricas o "transitividades de género bloqueadas por el sistema de género absolutamente enyesado de la colonial/modernidad" (Segato 2011, 33).

5 Según consta en el folleto de presentación. Crédito: Fondo Pola Weiss, Centro de Archivo y Documentación Arkheia, Museo Universitario de Arte Contemporáneo de la Universidad Nacional Autónoma de México.

6 Según consta en el gráfico original de la artista. Crédito: Fondo Pola Weiss, Centro de Archivo y Documentación Arkheia, Museo Universitario de Arte Contemporáneo de la Universidad Nacional Autónoma de México.

7 Según consta en el proyecto original de la artista. Crédito: Fondo Pola Weiss, Centro de Archivo y Documentación Arkheia, Museo Universitario de Arte Contemporáneo de la Universidad Nacional Autónoma de México.

8 Estas dimensiones recuerdan las "Formas PIAS", denominación elaborada por la artista Maris Bustamante en 1993, que remite a las iniciales de performance, instalación y ambientación. Las nuevas modalidades de percibir y abordar la realidad pueden detectarse en la década de 1970 en México y se encuentran en acciones, "cuya estructura rebasaba entonces cualquier forma aceptada" (Bustamante 2008, 134).

9 Se trata de Des femmes en mouvements hebdo, Bilbao 20-27 de octubre 1979 2 F 26 octubre 1979, supplément au numéro 1. Crédito: Fondo Pola Weiss, Centro de Archivo y Documentación Arkheia, Museo Universitario de Arte Contemporáneo de la Universidad Nacional Autónoma de México.

10 Sobre la vinculación directa del género con lo privado y con el control del sexo, María Lugones advierte la motivación ideológica de tal reduccionismo, planteado desde un mandato biológico. Así, la producción cognitiva de la modernidad “ha conceptualizado la raza como 'engenerizada' y al género como racializado de maneras particularmente diferenciadas entre los europeos-as/blancos-as y las gentes colonizadas/no blancas" (Lugones 2014, 35). Tanto la raza como el género son para la autora dos poderosas ficciones que cruzaron la vida social de las comunidades que soportaron la presión del sistema colonial/moderno característica de la cultura eurocéntrica que dominó nuestro continente.

\section{REFERENCIAS}

Bustamante, Maris. 2008. "Conditions, Roads, and Genealogies of Mexican Conceptualism, $1921-$ 1993". En Arte is not Vida: Actions by Artists of the Americas 1960-2000, editado por Déborah Cullen, 134-151. Nueva York: Museo del Barrio.

Butler, Judith. 2011. "Cuerpos que importan: sobre los límites materiales y el discurso del "'sexo'." En Estudios avanzados de performance, coordinado por Diana Taylor y Marcela Fuentes, 51-88. México: Fondo de Cultura Económica.

Cordero Reiman, Karen e Inda Sáenz. 2007. “Introducción." En Crítica feminista en la teoría e historia del arte, compilado por Karen Cordero Reiman e Inda Sáenz, 5-13. México, Universidad Iberoamericana. 
Debroise, Olivier, ed. 2007. La era de la discrepancia/The Age of Discrepancias: arte y cultura visual en México/Art and Visual Culture in México 1968-1997. México: Museo Universitario de Ciencias y Arte.

Gargallo, Francesca. 2004. Las ideas feministas latinoamericanas. México: Universidad de la Ciudad de México.

Lerner, Gerda. 1990. La creación del patriarcado. Barcelona: Crítica.

Lucero, María Elena. 2014. “Performance, estereotipo y género: algunas consideraciones desde el feminismo." Presentación en I Jornadas Interdisciplinarias sobre Estudios de Género y Visuales: La producción visual de la sexualidad, Universidad Nacional de Mar del Plata, Mar del Plata, abril 22-23.

Lugones, María. 2014. "Colonialidad y género: hacia un feminismo descolonial." En Género y descolonialidad, compilado por Walter Mignolo, 13-42. Buenos Aires: Del Signo.

Maier, Carol. 2008. "Traducción corpórea: meditaciones sobre la mediación". deSignis 12: 41-48.

Mercado, Ángel. s. f. “Videoarte de la tragedia: mi ojo es mi corazón." Fondo Pola Weiss, Centro de Archivo y Documentación Arkheia, Museo Universitario de Arte Contemporáneo, Universidad Nacional Autónoma de México.

Mercado, Tununa. s. f. "La venusina renace y reforma". Fondo Pola Weiss, Centro de Archivo y Documentación Arkheia, Museo Universitario de Arte Contemporáneo, Universidad Nacional Autónoma de México.

Mulvey, Laura. 2007. “El placer visual y el cine narrativo." En Crítica feminista en la teoría e historia del arte, coordinado por Karen Cordero Reiman e Inda Sáenz, 81-93. México: Universidad Iberoamericana.

Richard, Nelly. 2008. "Género". En Términos críticos de sociología de la cultura, dirigido por Carlos Altamirano, 95-101. Buenos Aires: Paidós.

Segato, Rita. 2011. "Género y colonialidad: en busca de claves de lectura y de un vocabulario estratégico descolonial." En Feminismos y poscolonialidad: descolonizando el feminismo desde y en América Latina, coordinado por Karina Bidaseca y Vanesa Vázquez Laba, 17-47. Buenos Aires: Godot.

Schneider, Rebecca. 2011. “El performance permanece". En Estudios avanzados de performance, coordinado por Diana Taylor y Marcela Fuentes, 215-240. México: Fondo de Cultura Económica.

\section{Cómo citar este artículo:}

Lucero, María Elena. 2017. "Pola Weiss, registrando cuerpos, movimientos y desbordes". Cuadernos de Música, Artes Visuales y Artes Escénicas 13 (1): 43-59. https://doi.org/10.11144/javeriana. mavae13-1.pwrTc 